\title{
Modeling and Optimization of Two Clays Acidic Activation for Phosphate Ions Removal in Aqueous Solution by Response Surface Methodology
}

\author{
Yao Joseph Adjoumani ${ }^{1,2^{*}}$ (D), Pierre Jean Marie Richard Dablé1, Konan Edmond Kouassi², \\ Soumahoro Gueu², Alain Stéphane Assémian², Kouassi Benjamin Yao²
}

${ }^{1}$ Laboratoire Thermodynamique, Traitement et Sciences des Surfaces et Interfaces, Ingénierie et Physicochimie des Procédés et de Mécaniques des Matériaux (L2TSIPM), Institut National Polytechnique Félix Houphouët Boigny INP H-B, Yamoussoukro, Côte d'Ivoire

${ }^{2}$ Laboratoire des Procédés Industriels de Synthèse et de l'Environnement (LAPISEN), Institut National Polytechnique Félix Houphouët Boigny INP H-B, Yamoussoukro, Côte d'Ivoire

Email: *yjadjoumani@yahoo.fr

How to cite this paper: Adjoumani, Y.J., Dablé, P.J.M.R., Kouassi, K.E., Gueu, S., Assémian, A.S. and Yao, K.B. (2019) Modeling and Optimization of Two Clays Acidic Activation for Phosphate Ions Removal in Aqueous Solution by Response Surface Methodology. Journal of Water Resource and Protection, 11, 200-216.

https://doi.org/10.4236/jwarp.2019.112012

Received: January 7, 2019

Accepted: February 19, 2019

Published: February 22, 2019

Copyright $\odot 2019$ by author(s) and Scientific Research Publishing Inc. This work is licensed under the Creative Commons Attribution International License (CC BY 4.0).

http://creativecommons.org/licenses/by/4.0/ c) (i) Open Access

\begin{abstract}
This work deals with phosphate ions removal in aqueous solution by adsorption carried out using two clays, both in activated form. One, non-swelling clay, rich in kaolinite, is associated with illite and quartz. The other, swelling, richer in montmorillonite, is associated with kaolinite, illite and quartz. Seven factors including these two clays were taken into account in a series of experimental designs in order to model and optimize the acidic activation process favoring a better phosphate removal. In addition to the choice of clay nature, the study was also interested in the identification of the mineral acid, between hydrochloric acid and sulfuric acid, which would promote this acidic activation. Response Surface Methodology (RSM) was used for this purpose by sequentially applying Plackett and Burman Design and Full Factorial Design (FD) for screening. Then, a central composite design (CCD) was used for modeling the activation process. A mathematical surface model has been successfully established. Thus, the best acidic activation conditions were obtained by activating the montmorillonite clay with a $2 \mathrm{~N}$ sulfuric acid solution, in an acid/clay mass ratio of 7.5 at $100^{\circ} \mathrm{C}$ for $16 \mathrm{H}$. The phosphate removal maximum rate obtained was estimated at $89.32 \% \pm 0.86 \%$.
\end{abstract}

\section{Keywords}

Clay Acidic Activation, Modeling, Optimization, Phosphate Removal, Response 
Surface Methodology

\section{Introduction}

Phosphorus is after nitrogen the fertilizing element that most often limits the development of crops [1]. For this reason, to improve crop yields, fertilization with soil is recommended [2]. In addition, phosphorus is also used for the manufacture of livestock feed as well as for the manufacture of detergents. Phosphorus is absorbed by plants in soil solution and in water as monovalent $\left(\mathrm{H}_{2} \mathrm{PO}_{4}^{-}\right)$ and divalent orthophosphate $\left(\mathrm{HPO}_{4}^{2-}\right)$ anions, each accounting for 50 percent of total phosphorus at neutral $\mathrm{pH}(\mathrm{pH}-7)$. At $\mathrm{pH} 4-6, \mathrm{HPO}_{4}^{2-}$ represents about 100 percent of the total phosphorus in solution. At $\mathrm{pH} 8, \mathrm{H}_{2} \mathrm{PO}_{4}^{-}$and $\mathrm{HPO}_{4}^{2-}$ represent respectively 20 percent and 80 percent of the total phosphorus [3]. The presence of phosphates in water, however, carries risks for aquatic fauna [4] and human health [5]. In fact, the excessive presence of nutrients (phosphate and nitrate) due to human activities disrupts the life cycle of aquatic environments and causes eutrophication [6]. Whether natural or anthropogenic, eutrophication causes several adverse effects on the aquatic ecosystem and human health due to the appearance of algae and cyanobacteria. It also increases the costs of water treatment [7]. According to the united Nation report [8], a part of the world's population lacking access to safe drinking water, continues to drink untreated surface water drawn from streams (river, backwater and lakes). It then becomes imperative to think to a prior treatment of wastewater before any discharge into watercourses or before any consumption. Many treatment techniques already exist in treatment plants.

There are biological treatments [9] and physicochemical processes, based on precipitation operations of calcium, iron or aluminum salts [10] or on coagulation, flocculation of aluminum sulfate [11]. All these techniques are complex and generate secondary sludge. They are so delicate to implement for the popularization of a wastewater treatment method.

In this context, adsorption appears to be an easy, more efficient and, above all, reusable technique by appropriate desorption processes [12]. Adsorption on materials such as clays might be of economic interest because of their abundance and relative ease of access [13]. These phosphate-loaded clays can also be used in agriculture as a phosphate fertilizer [14].

Acidic activation is one of the techniques used to improve the adsorption properties of clays [15]. It consists of replacing inter-foliar cations with protons to increase the adsorbent surface by increasing adsorption sites [16]. The chemical attack is therefore accompanied by a progressive dissolution of the structural cations $\left(\mathrm{Al}^{3+}, \mathrm{Mg}^{2+}\right.$ and $\left.\mathrm{Fe}^{3+}\right)$ and $\mathrm{Si}^{4+}$, respectively hosted in the octahedral and tetrahedral sites [17]. This dissolution can then lead to dislocation, see the collapse of the crystal lattice and the formation of amorphous silica [18] [19]. These 
structural changes depend on several factors, mainly the nature of clay and activation parameters [20].

It turns out that the studies of phosphate ions removal do not focus on optimizing the activation conditions favoring this adsorption. Activation factors are most often fixed, and the study focuses on the optimization of adsorptions parameters such as $\mathrm{pH}$, adsorption time, mass of sorbent, the normality of the sorbate [21] [22]. This present study is concerned with the optimization of the activation conditions. Experimental design were used for this purpose given the number of factors selected

Working tool that facilitates decision-making, experimental design is here used to optimize and modeling clays acidic activation. In this study, seven (7) factors that may influence acidic activation process were considered. These are the type and normality of the acid solution, the acid/clay mass ratio, the temperature and activation duration, the nature or the type of the clays as well as their granulometries. This work aims to model this activation process by the establishment of a predictive mathematical model and to determine the optimal conditions that would favor a better phosphate ions removal and investigate the interactions between the different factors.

Ultimately, what type of clay and mineral acid does the activation process promote? And under what conditions of acid normality, temperature and duration of activation will this be achieved? The interest of this study lies in the methodology used to achieve the expected objective. Response Surface Methodology (RSM) operated through Plackett and Burman Design (PBD), Full Factorial Design (FD) and Central Composite Design (CCD) are used for this purpose. The results obtained, compared with those of the literature on acid activation of montmorillonite and kaolinite, were used to judge the relevance of the methodology used.

The interest of this study lies in the fact that the clays used in this work, one swelling and the other non-swelling, were never used simultaneously for this type of work. The use of experimental designs made it possible to study for the first time the interactions between the factors influencing the acid activation process of clays for phosphate ions removal. Finally, the other element of interest derives from the modeling of this activation process which makes it possible to predict, depending on the nature of the clay and other factors such as the normality of the acid solution, the temperature and the duration of activation, the probability that acidic activation will contribute to promote phosphate ions capture.

\section{Material and Methods}

\subsection{Clay Extraction and Purification}

The Clays was collected from two cities of Côte d'Ivoire. One was collected at the northern in the savannah zone, on a site of geographical coordinates $08^{\circ} 08.94^{\prime} \mathrm{N}$ and $05^{\circ} 05.95^{\prime} \mathrm{W}$ [23]. This clay, rich in montmorillonite and associated with illite, 
kaolinite and quartz has been called MTMO for the following. The other comes from the deposit with coordinates $05^{\circ} 15^{\prime} \mathrm{N}$ and $04^{\circ} 20^{\prime} \mathrm{W}$ in the south, on the lagoon bank [24]. That one, rich in kaolinite, associated with illite and quartz is designed by KAO for the following. Samples were taken at a depth between 1.5 and $2 \mathrm{~m}$.

Each clay is separated into two granulometric fractions: One less than $50 \mu \mathrm{m}$ and the other less than $2 \mu \mathrm{m}$. The first phase is obtained by wet sieving. The powders are obtained after drying in an oven at $105^{\circ} \mathrm{C}$ and are denoted $\mathrm{MTMO}_{50}$ for the clay MTMO and $\mathrm{KAO}_{50}$ for the $\mathrm{KAO}$ clay. The second phase is extracted from the first according to the Holtzapffel protocol [25] based on the action of 50 volumes $\mathrm{H}_{2} \mathrm{O}_{2}(50 \%$, MERCK) followed by a $0.5 \mathrm{~N}$ hydrochloric acid solution (37\%, MERCK) treatment. These attacks aim to eliminate organic matter and carbonates respectively. The treatment is followed by washing this sample in a 1 M solution of sodium chloride (PROLABO) for 24 hours, three times and each time the exchange solution $(\mathrm{NaCl})$ was renewed. This treatment aims to facilitate the separation of clay particles from silts and fine sand and to promote homo-ionization. The granulometric phases of $2 \mu \mathrm{m}$ size noted $\mathrm{MTMO}_{2}$ and $\mathrm{KAO}_{2}$, are obtained in the last step by siphoning and drying the supernatant of the upper $20 \mathrm{~cm}$ of a test tube of $2 \mathrm{~L}$, after 24 hours of sedimentation.

\subsection{Activation Process}

The activation was carried out either with hydrochloric acid or with sulfuric acid in a reactor consisting of a three-necked flask of $500 \mathrm{~cm}^{3}$, surmounted by a refrigerant. The flask is kept stirring in a heat bath. The clay masses and the amounts of acid are set in various mass acid/clay ratios. The duration time $t$ of the activation is counted from the moment; the temperature in the flask reaches that fixed for the activation. The activated clay is then centrifuged at $4000 \mathrm{rpm}$ for 15 minutes and then washed with distilled water until acid is removed. Washing is stopped when the supernatant no longer gives any reaction of sulfates with barium chloride for activation with sulfuric acid and, in the case of hydrochloric acid, when silver nitrate test is negative. The activated clay is then dried at $105^{\circ} \mathrm{C}$.

\subsection{Adsorption Test}

Activation effectiveness is evaluated from the abatement rate $Y$ of the $\mathrm{H}_{2} \mathrm{PO}_{4}^{-}$ ions representing the removal rate of these ions, expressed in percentage; Equation (1).

$$
Y=\frac{C_{0}-C}{C_{0}} * 100
$$

$C_{0}$ and $C$ in $\mathrm{mg} \cdot \mathrm{L}^{-1}$, respectively represent the initial and residual mass concentrations of $\mathrm{H}_{2} \mathrm{PO}_{4}^{-}$ions.

Tests were carried out at $30^{\circ} \mathrm{C}$ in an oscillating water bath of JULABO SW1 type. Each time, $1 \mathrm{~g}$ of activated clays is introduced into a $100 \mathrm{~mL}$ flask containing 
$25 \mathrm{~mL}$ of a $40 \mathrm{mg} / \mathrm{L}$ synthetic $\mathrm{KH}_{2} \mathrm{PO}_{4}$ (MERCK) solution. The $\mathrm{pH}$ was adjusted at 4.7 using $1 \mathrm{~N}$ sulfuric acid solution or $1 \mathrm{M}$ sodium hydroxide solution according to previous works [26]. The adsorption time was set at 24 hours. Eventually, the mixture is centrifuged at $4000 \mathrm{rpm}$ for 15 minutes and then filtered $(0.45$ microns). Residual phosphate ions determination in the filtrate is carried out by spectrophotometry at $880 \mathrm{~nm}$ with a JASCO-type spectrophotometer, after the formation of the blue-colored phosphor-molybdic complex [27].

\subsection{Modeling and Optimization}

The optimization was carried out through Response Surface Methodology (RSM). This technique aims to quantitatively determine the response function variation represented in this study by the abatement rate $Y$, with respect to the factors having a significant influence [28] [29]. These influencing factors are first identified from a screening study. RSM and screening are the two main uses of design of experiments (DOE). DOE consist of offering few experiments while varying all the factors simultaneously in order to obtain as much information as possible [30]. This approach is diametrically opposed to the unitary method also called "one factor at a time" which consists in varying each factors, one after the other, by affecting all the possible values [30]. Since the response function is defined, the implementation of DOE begins with factors presentation, experimental domain definition, matrix design elaboration, essays execution in a random and ends with factors effects determination. The experimental domain is a range of variations allowed for the factor in which it will be possible to carry out the experiments. This range is delimited in a two-level experimental design, by the low level $(-1)$ and the high level $(+1)$. These levels are numbers in the case of a quantitative factor, and a state for a qualitative factor. The screening was carried out in this study after two experimental designs application, namely Plackett and Burmann Design (PBD) and the Full Factorial Design (FD). The development of the first is based on the seven-factor of Hadamard matrix. Table 1 shows the coded $\left(X_{i}\right)$ and non-coded $\left(U_{i}\right)$ values of the seven variables examined as well as

Table 1. Factors and Experimental Domain of Plackett and Burmann design.

\begin{tabular}{clcc}
\hline \multirow{2}{*}{ Coded variables $\left(X_{i}\right)$} & \multicolumn{1}{c}{ Factors $\left(U_{i}\right)$} & \multicolumn{2}{c}{ Experimental Domain } \\
\cline { 3 - 4 } & & Low level $(-1)$ & High level $(+1)$ \\
\hline$X_{1}$ & $U_{1}$ : Temperature $\left({ }^{\circ} \mathrm{C}\right)$ & 35 & 80 \\
$X_{2}$ & $U_{2}$ : Acid type & $\mathrm{H}_{2} \mathrm{SO}_{4}$ & $\mathrm{HCl}$ \\
$X_{3}$ & $U_{3}$ : Acid normality $(\mathrm{N})$ & 1 & 5 \\
$X_{4}$ & $U_{4}$ : Activation duration $(\mathrm{H})$ & 3 & 10 \\
$X_{5}$ & $U_{5}$ : Clay granulometry $(\mu \mathrm{m})$ & 2 & 50 \\
$X_{6}$ & $U_{6}$ : Mass ratio & 3.5 & 7.5 \\
$X_{7}$ & $U_{7}$ : Clay nature & montmorillonite & kaolinite
\end{tabular}

*The low $(-1)$ and high $(+1)$ levels represent limits of possible values or states of the factors. 
the experimental domain used for this design.

The matrix is obtained by right circular permutation of the basic pattern about seven factors: +++-+-- [31]. The last line is made up of signs -.The factors effects determination allowed establishing a relationship between the explained variable $Y$ response function and the explanatory variables representing the $X_{i}$ factors. This relationship is presented in the form of a $1^{\text {st }}$ degree model where all interactions between factors are neglected [32]. For seven (7) factors, the model is written as indicated by Equation (2):

$$
Y=b_{0}+\sum_{i=1}^{7} b_{i} X_{i}
$$

where, $b_{0}$ represents the constants (or average effect) of the model and bi the factors effects determined by the least square method or by software. The factors coefficients obtained at the end of this screening have helped to show the relevance of factors. The coefficient $b_{i}$ is statistically different from zero and the factor $X_{i}$ is considered for the following of the study if the absolute value of its $b_{i}$ coefficient is greater than two times the experimental standard deviation $\sigma_{e}$ [32]. The $\sigma_{e}$ value is given by Equation (3).

$$
\sigma_{e}=\frac{\sigma}{\sqrt{n}}
$$

$\sigma$ is the standard deviation of the repetitions average performed under the conditions of one of the tests if there is a qualitative factor or, from the test at the center if there are only quantitative factors [32].

The second experimental design used is the Full Factorial Design (FD; $\left.2^{k}\right)$ with the $k$ factors considered relevant from the previous design. FD allowed to investigate the possible interactions between these factors, to face modeling of the activation process by a first-degree model taking into account the interactions (Equation (4)), as well as to define the final experimental domain to be used for optimization [28].

$$
Y=b_{0}+\sum b_{i} X_{i}+\sum \sum b_{i j} X_{i} X_{j} ; i \neq j
$$

Here $b_{i j}$ represent the interaction effects of 2 order. At the end of the data processing, the Pareto diagram gives the effective contribution of each factor. These contributions are calculated with Equation (5):

$$
P_{i}=\frac{b_{i}^{2}}{\sum_{i=1}^{6} b_{i}^{2}}
$$

$b_{i}$ are the main coefficients and interaction coefficients. Experimental results led to a CCD with the $q$ factors having the highest contributions.

The CCD experiment matrix has been built using three sets of essays, including $2^{q}$ in FD, $2 \times q$ star essays and $\mathrm{n}$ central essays [28] [30].

Tests at the center will be used to estimate the experimental error and to enforce the optimality criteria characterized by the pseudo-orthogonality of the matrix and the isovariance of the response throughout the experimental domain. CCD allowed establishing a second-level model to describe the process being 
studied. The corresponding mathematical model is given in the form of Equation (6) below:

$$
Y=b_{0}+\sum b_{i} X_{i}+\sum \sum b_{i j} X_{i} X_{j}+\sum b_{i i} X_{i}^{2}+e ; i \neq j
$$

where $b_{i i}$ represents the coefficients of the squares and $e$ is a random error. The optimal conditions for activation are subsequently deduced.

A multiple linear regression program using the NEMROD-W 9901 French version software [33] is used to determine factor coefficients and all statistical estimates. The validation of models has been motivated by determination coefficients interpretation, $R^{2}$ and $R_{A}^{2}$ given by NEMROD-W. $R_{A}^{2}$ corresponds to the adjusted value of $R^{2}$. $R^{2}$ is defined as the ratio between the explained variance and the total variance [34]. The total variance takes into account the variance explained and that due to the residuals [30] [35]. $R_{A}^{2}$ always less than $R^{2}$, allows to consider the number of variables necessary for the theoretical model establishment because a high value of $R^{2}$ can sometimes be due to an excess of factors [35] [36]. According to Lambert et al. [37] and to Joglekar \& May [38], the model could be validated if $R^{2}$ is greater than 0.80 . But for Baudot [36] and Scibilia [35], adequacy between a theoretical model and experimental results must be accepted considering $R_{A}^{2}$ rather than $R^{2} ; R_{A}^{2}$ has to be greater than 0.77 .

These conclusions were tested by other statistical analysis tools such as Analysis Of Variance (ANOVA) or coefficient of variation C.V (Equation (7)) from the residuals which represent the difference between the experimental values and the values calculated from the predictive model.

$$
\mathrm{C} . \mathrm{V}=\frac{1}{N}\left[\sum_{i=1}^{N}\left|\frac{Y_{\text {exp }}-Y_{\text {calc }}}{Y_{\exp }}\right|\right] \times 100
$$

$N$ is the number of tests. According to these data, the model is accepted if the coefficient of variation is less than 5\% [39].

\section{Results and Discussions}

\subsection{Factors Screening}

\subsubsection{Plackett and Burman Design}

Table 2 presents Hadamard matrix, experimental design, response values $Y$ calculated using éq 1 , factors coefficients and experimental errors $2 \sigma_{e}$. The experimental standard deviation $\sigma_{e} 1.48$ was determined with the five-run repeat of the test 1; the values obtained as percentage of abatement being respectively 29.75; 28.25 and 24.75. The analysis of the coefficients suggests that the acid solution normality $\left(X_{3}\right)$, the duration of activation $\left(X_{4}\right)$ and clay's nature $\left(X_{7}\right)$ are the most influential factors. This result would support the idea that the acidic activation would depend on the nature of the clay [40], and that montmorillonite-rich clays would be more prone to acidic activation than those, richer in kaolinite [41].

According to Srasra et al. [42], and Christidis et al. [43], this is due to the acid activation that causes structural changes in the smectites. These changes, according 
Table 2. Experimental Hadamard matrix with phosphate removal rate.

\begin{tabular}{|c|c|c|c|c|c|c|c|c|c|c|c|c|c|c|c|}
\hline \multirow{3}{*}{$n^{\circ} \exp$} & \multicolumn{14}{|c|}{ Factors } & \multirow{3}{*}{$\begin{array}{c}\text { Phosphate } \\
\text { Removal } \\
Y_{\exp }(\%)\end{array}$} \\
\hline & \multicolumn{7}{|c|}{ Coded Variables } & \multicolumn{7}{|c|}{ Real Variables } & \\
\hline & $X_{1}$ & $X_{2}$ & $X_{3}$ & $X_{4}$ & $X_{5}$ & $X_{6}$ & $X_{7}$ & $U_{1}\left({ }^{\circ} \mathrm{C}\right)$ & $U_{2}$ & $U_{3}(\mathrm{~N})$ & $U_{4}(\mathrm{H})$ & $U_{5}(\mu \mathrm{m})$ & $U_{6}$ & $U_{7}$ & \\
\hline 1 & +1 & +1 & +1 & -1 & +1 & -1 & -1 & 80 & $\mathrm{HCl}$ & $5 \mathrm{~N}$ & 3 & 50 & 3.5 & MTMO & 28.75 \\
\hline 2 & -1 & +1 & +1 & +1 & -1 & +1 & -1 & 35 & $\mathrm{HCl}$ & $5 \mathrm{~N}$ & 10 & 2 & 7.5 & MTMO & 38.75 \\
\hline 3 & -1 & -1 & +1 & +1 & +1 & -1 & +1 & 35 & $\mathrm{H}_{2} \mathrm{SO}_{4}$ & $5 \mathrm{~N}$ & 10 & 50 & 3.5 & $\mathrm{KAO}$ & 22.5 \\
\hline 4 & +1 & -1 & -1 & +1 & +1 & +1 & -1 & 80 & $\mathrm{H}_{2} \mathrm{SO}_{4}$ & $1 \mathrm{~N}$ & 10 & 50 & 7.5 & MTMO & 58.75 \\
\hline 5 & -1 & +1 & -1 & -1 & +1 & +1 & +1 & 35 & $\mathrm{HCl}$ & $1 \mathrm{~N}$ & 3 & 50 & 7.5 & KAO & 23.75 \\
\hline 6 & +1 & -1 & +1 & -1 & -1 & +1 & +1 & 80 & $\mathrm{H}_{2} \mathrm{SO}_{4}$ & $5 \mathrm{~N}$ & 3 & 2 & 7.5 & KAO & 20 \\
\hline 7 & +1 & +1 & -1 & +1 & -1 & -1 & +1 & 80 & $\mathrm{HCl}$ & $1 \mathrm{~N}$ & 10 & 2 & 3.5 & KAO & 38.75 \\
\hline \multirow[t]{4}{*}{8} & -1 & -1 & -1 & -1 & -1 & -1 & -1 & 35 & $\mathrm{H}_{2} \mathrm{SO}_{4}$ & $1 \mathrm{~N}$ & 3 & 2 & 3.5 & MTMO & 42.5 \\
\hline & \multicolumn{7}{|c|}{ Coefficients } & $b_{1}$ & $b_{2}$ & $b_{3}$ & $b_{4}$ & $b_{5}$ & $b_{6}$ & $b_{7}$ & $b_{0}$ \\
\hline & \multicolumn{7}{|c|}{ Values } & 2.35 & -1.725 & -6.725 & 5.5 & -0.8 & 1.1 & -7.975 & 34.225 \\
\hline & \multicolumn{7}{|c|}{ Experimental error $2 \sigma_{e}$} & \multicolumn{8}{|c|}{2.96} \\
\hline
\end{tabular}

to them, induce an increase of their specific surface area and the average pore volume, thereby contributing to improving their adsorption and discoloration capacity. The other sample, consisting only of non-swelling clay (kaolinite and illite), for which the access of protons to their octahedral layers is strongly restricted, does not benefit from the effect of acid activation on adsorption.

However, the nature of the clay being a qualitative factor, it has been fixed for the continuation. From then on, we would have only two factors left. However, the temperature $\left(X_{1}\right)$ with a coefficient $\mathrm{b}_{1}$ of 2.35 close to $2 \times \sigma_{e}$, has been considered in the following as a relevant factor for this process. At the end of this screening, three factors were selected: Normality, temperature and duration of activation. This selection of factors is consistent with that of Gannouni et al. [18] and Haffane et al. [44] who present these three factors as the most relevant to conduct acidic activation of clays.

The normality of the acid solution, for example, influences the kinetics of attack [19] [45]. According to these authors, it is observed that more the acid solution is concentrated, shorter is the activation duration and lower is the temperature. Conversely, if the concentration is low, the activation duration is longer, and the temperature is higher. They often locate the temperature between 30 and $120^{\circ} \mathrm{C}$, the acid normality from $0.5 \mathrm{~N}$ to $20 \mathrm{~N}$, the activation duration from 3 to more than 20 hours; and the mass acid/clay ratios between 3 and 8 . Later on, the values of the non-influencing factors were fixed according to the experimental design methodology, at their low or high level, by considering the sign of their coefficient $b_{i}$ Thus, the optimization of the activation for this phosphate removal was sought by using the MTMO clay with $2 \mu \mathrm{m}$ particle size activated by sulfuric acid in an acid/clay mass ratio of 7.5.

The use of sulfuric acid for activation experiments agrees with those of other 
studies. In fact, Pushpaletha et al. [46] reported that the catalytic properties of their clay are improved when activation is carried out with sulfuric acid rather than with hydrochloric acid. Kara et al. [47] observed that the adsorption capacity of their clay increased after activation when they successively used the mineral acids, in the order: nitric acid, hydrochloric acid and sulfuric acid. Regarding particle size, the particle size fraction smaller than $2 \mu \mathrm{m}$ is better because it would contain more clay minerals than the sieve fraction at $50 \mu \mathrm{m}$ in which these minerals would remain buried in larger particles [48].

\subsubsection{Full Factorial Design (FD)}

This FD conducted with three factors was interpreted after eight $\left(2^{3}\right)$ essays. The experimental area of this design is defined as follows: The temperature factor $\left(U_{1}\right)$ with a low level set at $65^{\circ} \mathrm{C}$ and the high level at $90^{\circ} \mathrm{C}$; the normality factor $\left(U_{2}\right)$ with the low level $0.5 \mathrm{~N}$ and the high level $2 \mathrm{~N}$, then the activation duration factor $\left(U_{3}\right)$ with the low level $8 \mathrm{H}$ and the high level $12 \mathrm{H}$. Table 3 presents the matrix and experimental designs; test results and coefficients of variation.

The data processing with the software, gives the first-degree polynomial (Equation (8)). Figure 1 depicts the Pareto diagram highlighting the relevance of key factors and interactions.

Table 3. Experimental factorial matrix $\left(2^{3}\right)$ and phosphate removal rate.

\begin{tabular}{|c|c|c|c|c|c|c|c|c|c|}
\hline \multirow{3}{*}{$n^{\circ} \exp$} & \multicolumn{6}{|c|}{ Factors } & \multirow{3}{*}{$\begin{array}{c}\text { Phosphate } \\
\text { removal } \\
Y_{\exp }(\%)\end{array}$} & \multirow{3}{*}{$\begin{array}{c}\text { Theoretical } \\
\text { phosphate } \\
\text { removal } \\
Y_{\text {calc }}(\%)\end{array}$} & \multirow{3}{*}{$\begin{array}{l}\text { Coefficient of } \\
\text { variation } \\
(\%)\end{array}$} \\
\hline & \multicolumn{3}{|c|}{ Coded variables } & \multicolumn{3}{|c|}{ Real variables } & & & \\
\hline & $X_{1}$ & $X_{2}$ & $X_{3}$ & $U_{1}\left({ }^{\circ} \mathrm{C}\right)$ & $U_{2}(\mathrm{~N})$ & $U_{3}(\mathrm{H})$ & & & \\
\hline 1 & -1 & -1 & -1 & 65 & 0.5 & 8 & 31.25 & 34.22 & 9.5 \\
\hline 2 & +1 & -1 & -1 & 90 & 0.5 & 8 & 51.25 & 48.28 & 5.8 \\
\hline 3 & -1 & +1 & -1 & 65 & 2 & 8 & 38.75 & 35.78 & 7.66 \\
\hline 4 & +1 & +1 & -1 & 90 & 2 & 8 & 42.5 & 45.47 & 6.99 \\
\hline 5 & -1 & -1 & +1 & 65 & 0.5 & 12 & 43.75 & 40.78 & 6.79 \\
\hline 6 & 1 & -1 & +1 & 90 & 0.5 & 12 & 53.76 & 56.72 & 5.51 \\
\hline 7 & -1 & +1 & +1 & 65 & 2 & 12 & 43.75 & 46.72 & 6.79 \\
\hline 8 & +1 & +1 & +1 & 90 & 2 & 12 & 61.25 & 58.28 & 4.85 \\
\hline
\end{tabular}

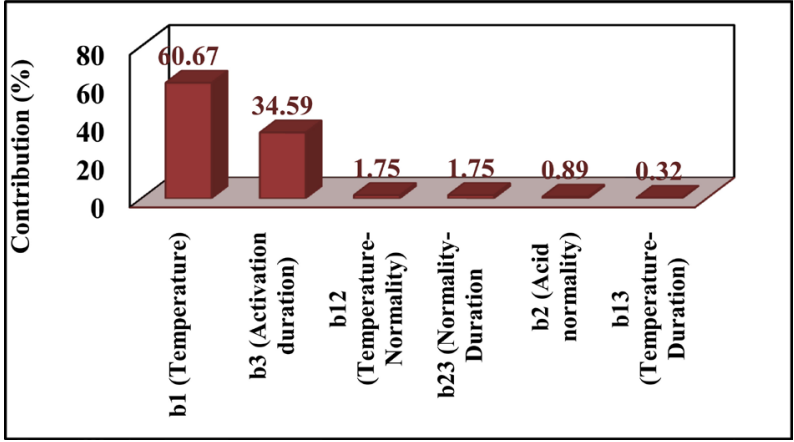

Figure 1. Pareto diagram giving factors contributions and their interactions. 


$$
Y=45.78+6.41 X_{1}+0.78 X_{2}+4.84 X_{3}-1.09 X_{1} X_{2}+0.47 X_{1} X_{3}+1.09 X_{2} X_{3}
$$

According to Figure 1, only the temperature $\left(X_{1}\right)$ and the activation duration $\left(X_{3}\right)$ have the highest contributions. The interactions between the factors as well as the contribution of normality remain marginal because their effects are statistically null. Temperature and activation duration appear as the most relevant in the activation process for $\mathrm{H}_{2} \mathrm{PO}_{4}^{-}$ions removal. Their global contribution is $95.26 \%$ corresponding to $60.67 \%$ for temperature and $34.59 \%$ for the activation duration.

This result agrees with the observations of Khoek et Lim [45] and Tyagi et al. [19]. They reported that the temperature and the duration of activation are higher as the concentration of the acid is low. Indeed, the acid solution normality fixed in this FD between 0.5 and $2 \mathrm{~N}$, can be considered low compared to extreme values used up to $20 \mathrm{~N}$ [19] [45]. Under these conditions, the temperature and the duration of activation remain the factors, which control this activation process. Sulfuric acid solution normality was set at $2 \mathrm{~N}$, taking to account positive sign of the coefficient $b_{2}$.

Validation of the first-degree model was examined based on the statistical data provided by the NEMROD software through ANOVA. These include the coefficients of determination $R^{2}$ and $R_{A}^{2}$ with respective values of 0.885 and 0.194 , the average of the coefficient of variation of $6.73 \%$, the contribution of residues of $11.51 \%$ in the total sum of the squares and $58.6 \%$ of model significance. These data do not allow to validate this model because although $R^{2}$, lower than 0.80 is acceptable [37] [38], the other indices are not likely to allow this validation. Indeed, the coefficient of variation [39] and the sum of the squares due to residuals [30] are not less than 5\%. A CCD was then conducted with the two most influential factors highlighted by the Pareto diagram namely the temperature and the duration of activation. The very low value of $R_{A}^{2}$ less than 0.77 , shows that the use of three factors for process modeling was excessive and would confirm the importance of $R_{A}^{2}$ [35] [36].

\subsection{Modeling and Optimization}

With the two factors those are temperature and activation duration $(q=2)$, the CCD consisted of four FD tests, four in-star tests and five central essays [30]. Each factor is ranged between $-r$ and $+r$ equal to $2^{q / 4}$ i.e. between -1.414 unit and +1.414 unit. These coded values translate into real values $50^{\circ} \mathrm{C}$ and $100^{\circ} \mathrm{C}$ chosen as the limit of the experimental domain for the temperature $\left(U_{1}\right) ; 8$ hours and 16 hours for the duration $\left(U_{2}\right)$. The explored experimental domain and the levels attributed to each variable are presented in Table 4 [32].

Table 4. Variables and experimental domain of CCD.

\begin{tabular}{cccccc}
\hline & $-r=-1.414$ & -1 & 0 & +1 & $+r=+1.414$ \\
$X_{1}\left({ }^{\circ} \mathrm{C}\right)$ & 50 & 57 & 75 & 93 & 100 \\
$X_{2}(\mathrm{H})$ & 8 & 9 & 12 & 15 & 16 \\
\hline
\end{tabular}


Test results, predicted responses, residuals, and percentages of deviation are shown in Table 5; the FD tests are shown in tests 1 to 4 , star and center tests respectively in tests 5 to 8 and 9 to 13 .

Equation (9) represents the theoretical response of the abatement rate of phosphate removal.

$$
Y=43.120+6.380 X_{1}+10.901 X_{2}+10.901 X_{1}^{2}+4.775 X_{2}^{2}+3.718 X_{1} X_{2}
$$

The coefficients of determination associated with this model, given by the NEMROD software are 0.952 for $R^{2}$ and 0.917 for $R_{A}^{2}$ all higher than respectively to 0.80 and 0.77 and the average of the deviation percentages $2.67 \%$, which is less than $5 \%$. These statistical results show that the 2-degree polynomial model proposed for modeling the clay activation for $\mathrm{H}_{2} \mathrm{PO}_{4}^{-}$ions removal is satisfactory. This conclusion is supported by the analysis of the variance (ANOVA) for the predicted response (Equation (9)) of this process as reported in Table 6.

Table 5. Experimental design and results of the central composite matrix.

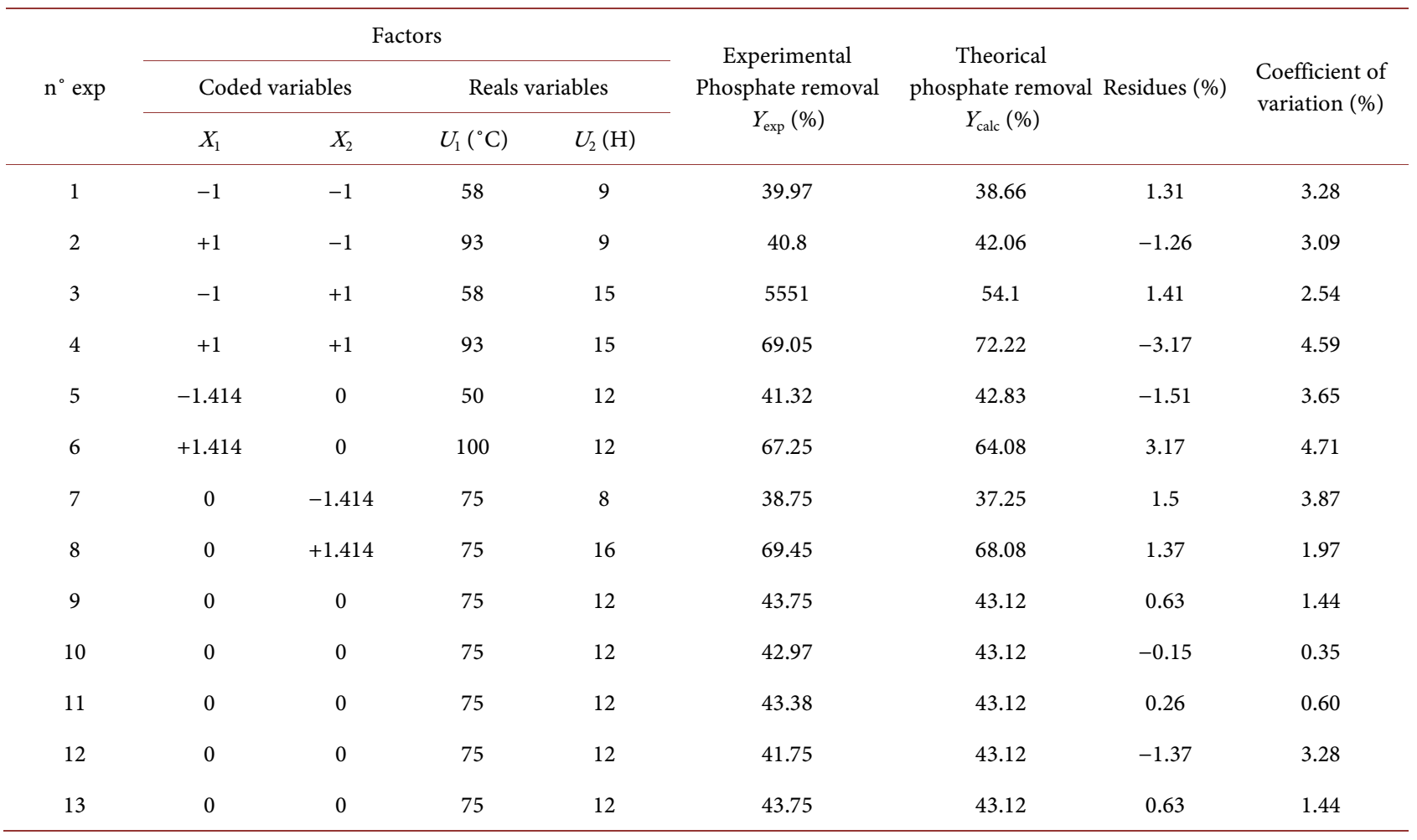

Table 6. ANOVA for phosphate removal by adsorption on MTMO activated clay.

\begin{tabular}{|c|c|c|c|c|c|}
\hline Source of variation & Sum of squares & Freedom degree & Middle square & Ratio & Significance \\
\hline Regression & 1602.76 & 5 & 320.553 & 464.4344 & $* * *$ \\
\hline Residue & 81.3053 & 7 & 11.615 & & \\
\hline Validity & 78.5445 & 3 & 26.1815 & 37.9332 & ** \\
\hline Error & 2.76 & 4 & 0.6902 & & \\
\hline total & 1684.0653 & 12 & & & \\
\hline
\end{tabular}


Table 6 indicates that the sum of the squares of the residuals that is 81.3053 is smaller than a third of the sum of the squares of the regression equal to 534.25 with a high rate of significance materialized by the three stars (Tinsson, 2010). It also indicates that the sum of the squares due to the error in the residuals is worth i.e. only $3.39 \%$ or $0.16 \%$ of the sum of the squares. Then, it appears that these errors can be neglected. The model expressed by Equation 9 can effectively be used to describe correctly the process studied.

The theoretical response area depicted in Figure 2 indicates that the maximum rate of abatement that can be achieved is $93.20 \%$

Resolution of Equation (9) indicates that this theoretical maximum is obtained with temperature equal to +1.414 in coded value i.e. $100^{\circ} \mathrm{C}$ in real value and duration of activation of +1.414 i.e. $16 \mathrm{H}$. The high duration obtained is related to the low acidic solution concentration. Indeed, Jahouach [49] reported that discoloration of olive oils by activated clays with a $15 \mathrm{~N}$ concentrated sulfuric acid at $70^{\circ} \mathrm{C}$ has only needed $3 \mathrm{H}$ for the optimization of its process. Besides, Adjia [50] found that the adsorption of heavy metals from wastewater by clay occurs at $30^{\circ} \mathrm{C}$ with a $0.5 \mathrm{~N}$ hydrochloric acid solution for 24 hours.

For the confirmation of the process studied here, three additional control tests were carried out with the activated montmorillonite clay sample under the conditions defined by the coordinates of the theoretical optimum (Table 7). The phosphate captures obtained are $88.65 \%$; $89.03 \%$ and $90.30 \%$ whose average is $89.32 \%$. The standard deviation of 0.86 and a coefficient of variation representing

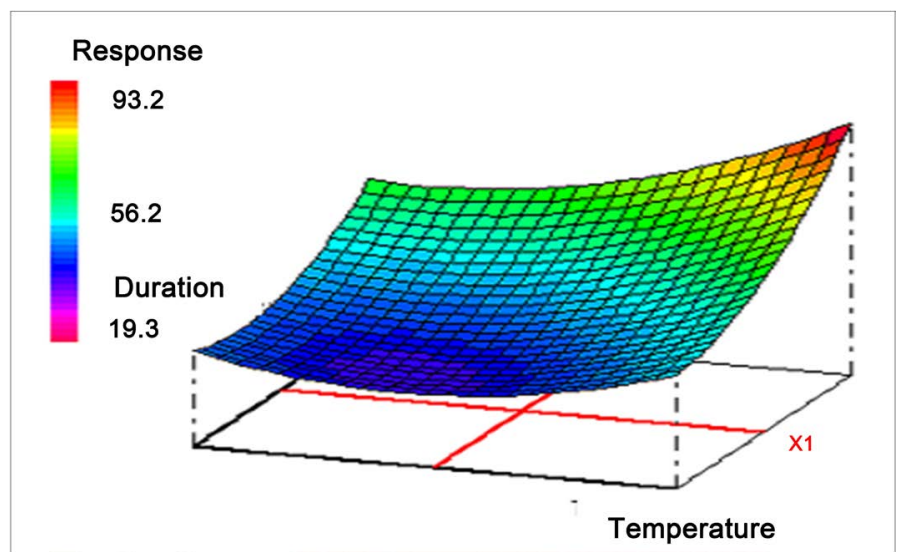

Figure 2. Response surface for optimization of adsorption of $\mathrm{H}_{2} \mathrm{PO}_{4}^{-}$.

Table 7. Determination of optimal condition proposed by Nemrod W Software and validation tests.

\begin{tabular}{|c|c|c|c|c|c|c|c|}
\hline \multirow{3}{*}{$n^{\circ} \exp$} & \multicolumn{4}{|c|}{ Factors } & \multirow{3}{*}{$\begin{array}{c}\text { Theorical } \\
\text { phosphate removal } \\
Y_{\text {calc }}(\%)\end{array}$} & \multirow{3}{*}{$\begin{array}{c}\text { Experimental Phosphate } \\
\text { removal } Y_{\exp } \\
(\%)\end{array}$} & \multirow{3}{*}{$\begin{array}{c}\text { Average Experimental } \\
\text { Phosphate removal } Y_{\text {exp }} \\
(\%)\end{array}$} \\
\hline & \multicolumn{2}{|c|}{ Coded variables } & \multicolumn{2}{|c|}{ Reals variables } & & & \\
\hline & $X_{1}$ & $X_{2}$ & $U_{1}\left({ }^{\circ} \mathrm{C}\right)$ & $U_{2}(\mathrm{H})$ & & & \\
\hline 14 & +1.414 & +1.414 & 100 & 16 & 93.30 & 88.65 & \\
\hline 15 & +1.414 & +1.414 & 100 & 16 & 93.30 & 89.03 & 89.32 \\
\hline 16 & +1.414 & +1.414 & 100 & 16 & 93.30 & 90.30 & \\
\hline
\end{tabular}


$4.26 \%$ compared to the theoretical maximum of $93.20 \%$, less than $5 \%$ validates the conclusions of this optimization although there is a difference between them. This difference taken into account by the model through the ANOVA revealed according to Table 6 that the sum of the squares due to the error in the residues is worth only $3.39 \%$ corresponding to $0.16 \%$ of the sum of the square.

\subsection{Comparison Tests between Activated and Non-Activated Clays}

Figure 3 presents with standard deviations, the $\mathrm{H}_{2} \mathrm{PO}_{4}^{-}$ion removal percentage using non-activated clays $\mathrm{MTMO}_{50}, \mathrm{MTMO}_{2}$ and activated clay $\mathrm{MTMO}_{2 \mathrm{~A}}$, obtained under the optimal activation conditions with $\mathrm{MTMO}_{2}$.

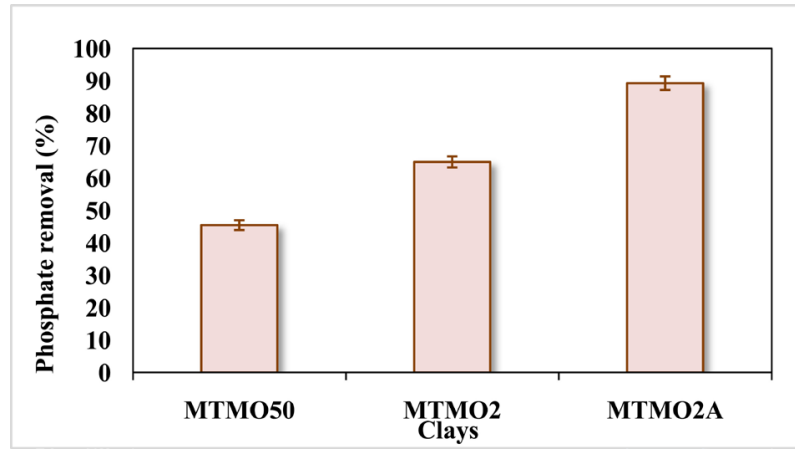

Figure 3. Phosphate removal percentages with non-activated $\mathrm{MTMO}_{50}$ and $\mathrm{MTMO}_{2}$ and activated $\mathrm{MTMO}_{2 \mathrm{~A}}$ clay samples.

This Figure shows that lower particle sizes improve phosphate ion removal. Phosphate removal percentage increases from $45.51 \% \pm 0.79 \%$ to $65.02 \% \pm 0.81 \%$ respectively for $\mathrm{MTMO}_{50}$ and $\mathrm{MTMO}_{2}$. In fact, clay treatment favors aluminum-silicon chemical binding breaks. So, sites where $\mathrm{H}_{2} \mathrm{PO}_{4}^{-}$ions can be adsorbed increases. Due to their lower size, $\mathrm{MTMO}_{2}$ clay offers more active sites for phosphate ion adsorption and the phosphate removal increase for this sample. These sites could be the non-satisfied valences $(+\mathrm{Al}-\mathrm{OH})$ of broken bindings in layer edges according to Wey [51] and Garcia [52]. Acidic activation which favors bindings breaks increase non-satisfied valences sites [53]. Consequently, more phosphate ions are involved in adsorption reaction. Then, phosphate removal increases up to $89.32 \%$ with $\mathrm{MTMO}_{2 \mathrm{~A}}$.

\section{Conclusion}

This study aimed to determine the optimal conditions for acidic activation of two clays respectively rich in montmorillonite and kaolinite for dihydrogen phosphate ions removal in aqueous solution through surface response methodology. Seven factors that are acidic solution type and normality; activation duration and temperature; nature and particle size of the clays as well as the ac$\mathrm{id} /$ clay mass ratio were considered for this purpose. A preliminary screening study showed the interest of working with montmorillonite clay for which acid activation was beneficial as opposed to kaolinite-rich clay. The activation process 
was subsequently interpreted using a CCD by a second order polynomial model. Optimal activation conditions are finally summarized in the use of Montmorillonite clay of $2 \mu \mathrm{m}$ particle size, activated with $2 \mathrm{~N}$ sulfuric acid, in a mass ratio of 7.5 at $100^{\circ} \mathrm{C}$ for $16 \mathrm{H}$. An abatement rate of $89.32 \%$ with a standard deviation of 0.86 was achieved under these conditions. This work ultimately determined, depending on the nature of the clay and other acid activation factors, the likelihood that acidic activation of clay would favor phosphate ions removal.

\section{Acknowledgements}

Our acknowledgements go to the Heads of the Laboratories of Soil Mechanics, the Laboratory of Pedology and the Laboratory of Industrial Processes Synthesis and New Energies of the National Polytechnic Institute Felix Houphouet Boigny of Yamoussoukro for the framework.

\section{Conflicts of Interest}

The authors declare no conflicts of interest regarding the publication of this paper.

\section{References}

[1] Eltelib, H.A., Hamad, M.A. and Ali, E.E. (2006) The Effect of Nitrogen and Phosphorus Fertilization on Growth, Yield and Quality of Forage Maize (Zea mays L.). Journal of Agronomy, 5, 515-518. https://doi.org/10.3923/ja.2006.515.518

[2] FAO (1984) Fertilizer and Plant Nutrition Guide. FAO Fertilizer and Plant Nutrition Bulletin No. 9, Rome.

[3] Black, C.A. (1968) Soil-Plant Relationships. John Wiley and Sons, Inc., New York.

[4] Barroin, G. (2003) Gestion des risques, santé et environnement: Le cas des nitrates, phosphore, azote et prolifération des végétaux aquatiques. Assises internationales envirobio 13-14/11/2000 Paris Le Courrier de l'Environnement (48). http://www7.inra.fr/dpenv/barroc48.htm

[5] Pitois, S., Jackson, M. and Wood, B. (2001) Sources of the Eutrophication Problems Associated with Toxic Algae: An Overview. Journal of Environmental Health, 64, 25-32.

[6] Kalff, J. (2002) Limnology. Land Water Ecosystems. Prentice Hall, Upper Saddle River, NJ. https://trove.nla.gov.au/version/40255631

[7] Chambers, P.A., Kent, R., Charlton, M.N., Guy, M., Gagnon, C., Roberts, E., Grove, E., and Foster, N. (2001) Les éléments nutritifs et leurs effets sur l'environnement au Canada. Environment Canada, Ottawa (Ont.). http://publications.gc.ca/pub?id=9.640297\&sl=1

[8] UN WATER (2017) The United Nations World Water Development Report 2017. Wastewater-The Untapped Resource. http://creativecommons.org/licenses/by-sa/3.0/igo/

[9] Rejsek, F. (2002) Analyse des eaux: Aspects réglementaires et techniques. Centre régional de documentation pédagogique (CRDP) d'Aquitaine. Coll. Biologie technique. Sciences et techniques de l'environnement.

[10] Zran, E., Yao, B., Trokourey, A., Yobouet, A. and Drogui, P. (2015) An Optimized Pathway for Phosphate Ions Removal from Aqueous Solution Based on Experimental Design Methodology. International Journal of Environmental Science and 
Technology, 12, 3117-3124. https://doi.org/10.1007/s13762-014-0738-1

[11] Moletta, R. (2002) Gestion des problèmes environnementaux dans les industries agroalimentaires. FRA, Paris. Lavoisier Tec et Doc.

https://prodinra.inra.fr/record/68168

[12] Mahmud, H., Huq, A.O. and Binti, Y.R. (2016) The Removal of Heavy Metal Ions from Wastewater Aqueous Solution Using Polypyrrole-Based Adsorbents. RSC Advances, 6, 14778-14791. https://doi.org/10.1039/C5RA24358K

[13] Bennani, K.A., Mounir, B., Hachkar, M., Bakasse, M. and Yaacoubi A. (2015) Adsorption of Cationic Dyes onto Moroccan Clay: Application for Industrial Wastewater Treatment. Journal of Materials and Environmental Science, 6, 2483-2500.

[14] Zhang, T., Ding, L., Ren, H., Guo, Z. and Tan, J. (2010) Thermodynamic Modeling of Ferric Phosphate Precipitation for Phosphorus Removal and Recovery from Wastewater. Journal of Hazardous Materials, 176, 444-450.

https://doi.org/10.1016/j.jhazmat.2009.11.049

[15] Zheng, Y. and Wang, A. (2009) Evaluation of Ammonium Removal Using a Chitosan-g-poly (Acrylic Acid)/Rectorite Hydrogel Composite. Journal of Hazardous Materials, 171, 671-677. https://doi.org/10.1016/j.jhazmat.2009.06.053

[16] Mokaya, R. and Jones, W. (1995) Pillared Clays and Pillared Acid-Activated Clays: A Comparative Study of Physical, Acidic Properties. Journal of Catalysis, 153, 76-85. https://doi.org/10.1006/jcat.1995.1109

[17] Novakovic, T., Rozic, L. and Petrovic, S. (2008) Synthesis and Characterization of Acid-Activated Serbian Smectite Clays Obtained by Statistically Designed Experiments. Chemical Engineering Journal, 137, 436-442. https://doi.org/10.1016/j.cej.2007.06.003

[18] Gannouni, A., Bellagi, A. and Bagane, M. (1999) Préparation d'une argile activée pour la décoloration de l'huile d'olive. Annales de Chimie Science des Matériaux, 24, 407-416. https://doi.org/10.1016/S0151-9107(99)80085-3

[19] Tyagi, B., Chudasama, C.D. and Jasra, R.V. (2006) Determination of Structural Modification in Acid Activated Montmorillonite Clay by FT-IR Spectroscopy, Spectrochim. Spectrochimica Acta Part A: Molecular and Biomolecular Spectroscopy, 64, 273-278. https://doi.org/10.1016/j.saa.2005.07.018

[20] Arfaoui, S., Frini-srasra, N. and Srasra, E. (2008) Modelling of the Adsorption of the Chromium Ion by Modified Clays. Desalination, 222, 474-481. https://doi.org/10.1016/j.desal.2007.03.014

[21] Ye, J., Cong, X., Zhang, P., Zeng, G., Hoffmann, E., Liu, Y., Wu, Y., Zhang, H., Fang, W. and Hahn, H.H. (2016) Application of Acid-Activated Bauxsol for Wastewater Treatment with High Phosphate Concentration: Characterization, Adsorption Optimization, and Desorption Behaviors. Journal of Environmental Management, 167, 1-7. https://doi.org/10.1016/j.jenvman.2015.11.023

[22] Wang, Y., He, H., Zhang, N., Shimizu, K. and Lei, Z. (2018) Efficient Capture of Phosphate from Aqueous Solution Using Acid Activated Akadama Clay and Mechanisms Analysis. Water Science \& Technology, 78, 1603-1614.

[23] Kpangni, E.B., Andji, Y.Y.J., Adouby, K., Oyetola, S., Kra, G. and Yvon, J. (2008) Mineralogy of Clayraw Materials from Côte d'Ivoire: Case of the Deposit from Katiola. Journal of Applied Sciences, 8, 871-875. https://doi.org/10.3923/jas.2008.871.875

[24] Emeruwa, E., Kouadio, K.C., Kouakou, C.H., Boffoue, O.M., Assande, A.A., Ouattara, S., Coulibaly, Y., Dauscher, A. and Lenoir, B. (2008) Caractérisation des argiles de la région d'Abidjan: Etude comparée de quelques gites et leur perspective de 
valorisation. Journal Ivoirien des Sciences et Technologie, 11, 177-192.

[25] Holtzapffel, T. (1985) Les mineraux argileux: Preparation, analyse diffractometrique et determination. Annales de la Société géologique du Nord, 12, 15-43.

[26] Dablé, P.J.M.R., Adjoumani, Y.J., Yao, B. and Ado, G. (2008) Wastewater Dephosphorization Using Crude Clays. International Journal of Environmental Science and Technology, 5, 35-42.

[27] AFNOR (1994) Essais des Eaux. Dosage des phosphates, des polyphosphates et du phosphore total (méthode spectrométrique). Qualité de l'eau. Association Française de normalisation, Paris, 356-361.

[28] Goupy, J. (2006) Les plans d'expériences. Revue Modulad, 34, 74-116. http://www.modulad.fr/archives/numero-34/Goupy-34/goupy-34.pdf

[29] Box, G.E.P. and Draper, N.R. (1987) Empirical Model-Building and Response Surfaces. John Wiley \& Sons, New York.

[30] Tinsson, W. (2010) Plans d'experience: Constructions et analyses statistiques. Springer, Berlin.

[31] Plackett, R.L. and Burmann, J.P. (1943) Design of Optimum Multifactorial Experiments. Biometrika, 33, 305-325.

[32] Feinberg, M. (1996) La validation des méthodes d'analyse: Une approche chimiométrique de l'assurance qualité au laboratoire.

[33] Mathieu, D., Nony, J. and Phan-Tan-Luu, R. (1998) New Efficient Methodology for Research Using Optimal Design (NEMROD) Software.

[34] Bailly, P. and Carrère, C. (2015) Statistiques descriptives. L'économie et les chiffres Presses universitaires de Grenoble, coll. Libres cours économie.

[35] Scibilia, B. (2018) Régression multiple: Quand utiliser le $\mathrm{R}^{2}$ ajusté ou le $\mathrm{R}^{2}$ prévu? http://www.minitab.com/fr-fr/Published-Articles/Regression-multiple-R2-ajuste-R2 -prevu/

[36] Baudot, J.Y. (2018) Le coefficient de détermination. http://www.jybaudot.fr/Correl_regress/coeffdeterm.html

[37] Lambert, A., Drogui, P., Daghrir, R., Zaviska, F. and Benzaazoua, M. (2014) Removal of Copper in Leachate from Mining Residues Using Electrochemical Technology. Journal of Environmental Management, 133, 78-85. https://doi.org/10.1016/j.jenvman.2013.11.036

[38] Joglekar, A.M. and May, A.T. (1987) Product Excellence through Design of Experiments. Cereal Foods World, 32, 857-868.

[39] Mundra, P., Desai, K. and Lele, S.S. (2007) Application of Response Surface Methodology to Cell Immobilization for the Production of Palatinose. Bioresource Technology, 98, 2892-2896. https://doi.org/10.1016/j.biortech.2006.09.046

[40] Neji, S.B., Trabelsi, M. and Frikha, M.H. (2009) Activation d'une argile smectite tunisienne à l'acide sulfurique: Rôle catalytique de l'acide adsorbé par l'argile. Journal de la Société Chimique de Tunisie, 11, 191-203. http://www.sctunisie.org/pdf/JSCT_v11-24.pdf

[41] Nguetnkam, J.P., Kamga, R., Villiéras, F., Ekodeck, G.E., Raza, A. and Yvon, J. (2011) Alteration of Cameroonian Clays under Acid Treatment. Comparison with Industrial Adsorbents. Applied Clay Science, 52, 122-132.

https://doi.org/10.1016/j.clay.2011.02.009

[42] Srasra, E., Bergaya, F., Van Damme, H. and Ariguib, N.K. (1989) Surface Properties of an Activated Bentonite-Decolorisation of Rape-Seed Oils. Applied Clay Science, 
4, 411-421. https://doi.org/10.1016/0169-1317(89)90019-7

[43] Christidis, G.E., Scott, P.W. and Dunham, A.C. (1997) Acid Activation and Bleaching Capacity of Bentonites from the Islands of Milos and Chios, Aegean, Greece. Applied Clay Science, 12, 329-347. https://doi.org/10.1016/S0169-1317(97)00017-3

[44] Haffane, S., Achak, O. and Chafik, T. (2016) Investigation of the Effect of Purification and Modification of a Local Clay on Its Structural and Textural Properties. Journal of Materials and Environmental Science, 7, 525-530.

[45] Khoek, S.C. and Lim, E.E. (1982) Mechanism of Palm Oil Bleaching by Montmorillonite Clay Activated at Various Acid Concentrations. Journal of the American Oil Chemists' Society, 59, 129-131. https://doi.org/10.1007/BF02662259

[46] Pushpaletha, P., Rugmini, S. and Lalithambika, M. (2005) Correlation between Surface Properties and Catalytic Activity of Clay Catalysts. Applied Clay Science, 30, 141-153. https://doi.org/10.1016/j.clay.2005.03.011

[47] Kara, M., Yuzer, H., Sabah, E. and. Celik, M.S. (2003) Adsorption of Cobalt from Aqueous Solutions onto Sepiolite. Water Research, 7, 224-232. https://doi.org/10.1016/S0043-1354(02)00265-8

[48] Belibi Belibi, P., Nguemtchouin, M.M.G., Rivallin, M., NdiNsami, J., Sieliechi, J., Cerneaux, S., Ngassoum, M.B. and Cretin, M. (2015) Microfiltration Ceramic Membranes from Local Cameroonian Clay Applicable to Water Treatment. Ceramics International, 41, 2752-2759. https://doi.org/10.1016/j.ceramint.2014.10.090

[49] Jahouach, W. (2009) Etude Des propriétés physico-chimiques des huiles d'olive et de grignon décolorés par des argiles tunisiennes activées aux ondes ultrsonores. PhD Dissertation, Université de Sfax, Tunisie.

[50] Adjia, Z.H. (2012) Adsorption des métaux lourds par les argiles alluviales de l'extrême-nord Cameroun. $\mathrm{PhD}$ Dissertation, co-supervised Université de Lorraine (France) and Université de N'Gaoundéré (Cameroun).

[51] Wey, R. (1955) Sur l'adsorption en milieu acide d'ions $\mathrm{H}_{2} \mathrm{PO}_{4}{ }^{-}$par la montmorillonite. Bulletin du Groupe français des Argiles, 6, 31-34.

http://www.persee.fr/doc/argil_0429-3320_1955_num_6_1_1259 https://doi.org/10.3406/argil.1955.1259

[52] Garcia, C. and Parigot, P. (1968) Boues et forage (Les).

[53] Boudjema, S. (2015) Synthèse de polyoxométalates à base de vanaduim et/ou de ruthénium. Application de l'époxydation du cyclohexéne, $\mathrm{PhD}$ Dissertation, Université de Tlemcen, Algérie. 